\title{
ANALISIS FAKTOR YANG BERPENGARUH TERHADAP IPM MENGGUNAKAN REGRESI LINEAR BERGANDA
}

\author{
Zakiyatul Fitriyah ${ }^{1}$, Syafira Irsalina ${ }^{2}$, Aditya Rizq Herlandy $\mathrm{K}^{3}$, Edy Widodo ${ }^{4}$ \\ ${ }^{1234}$ Statistika, Fakultas Matematika dan Ilmu Pengetahuan Alam, Universitas Islam Indonesia \\ 18611102@students.uii.ac.id ${ }^{1}, 18611105 @$ students.uii.ac.id ${ }^{2}$, \\ 18611107@students.uii.ac.id ${ }^{3}$, edywidodo@uii.ac.id ${ }^{4}$
}

\begin{abstract}
Development becomes a tool to achieve the goals of a nation. Meanwhile, to determine the success of a country's development, economic growth is used as an indicator. HDI is a measuring tool to determine the level of development of a region. Indonesia's HDI is included in the high category, including the provinces of West Java and Banten. There are allegations that the Covid-19 pandemic that occurred in 2020 affected the factors that formed the HDI. This study aims to determine the description of HDI and the influence of factors forming HDI consisting of AHH, RLS, HLS and per capita expenditure. The secondary data used is sourced from the Central Statistics Agency (BPS) of the Republic of Indonesia. This research method is multiple regression analysis. Based on the results of the study, the partial test showed that the variables AHH, RLS, HLS and per capita expenditure had a significant positive effect on the Regency/City HDI variable in the Provinces of West Java and Banten in 2020.
\end{abstract}

Keywords: HDI, Multiple Linear Regression, West Java and Banten

\begin{abstract}
Abstrak
Pembangunan menjadi suatu alat untuk mencapai tujuan suatu bangsa. Sedangkan untuk mengetahui keberhasilan pembangunan suatu negara digunakan pertumbuhan ekonomi sebagai salah satu indikator. IPM menjadi alat ukur untuk menentukan level pembangunan suatu wilayah. IPM Indonesia termasuk dalam kategori tinggi, tak terkecuali Provinsi Jawa Barat dan Banten. Terdapat dugaan bahwa pandemi Covid-19 yang terjadi tahun 2020 mempengaruhi faktor - faktor pembentuk IPM. Penelitian ini bertujuan untuk mengetahui gambaran IPM serta pengaruh faktor pembentuk IPM terdiri dari AHH, RLS, HLS dan pengeluaran per kapita. Data sekunder yang digunakan bersumber dari Badan Pusat Statistik (BPS) Republik Indonesia. Metode penelitian ini adalah analisis regresi berganda. Berdasarkan hasil penelitian, pada uji parsial menunjukkan variabel AHH, RLS, HLS dan pengeluaran per kapita, memiliki pengaruh positif secara signifikan terhadap variabel IPM Kabupaten/Kota di Provinsi Jawa Barat dan Banten pada tahun 2020.
\end{abstract}

Kata kunci: IPM, Regresi Linear Berganda, Jawa Barat dan Banten 
Jurnal Lebesgue: Jurnal Ilmiah Pendidikan Matematika, Matematika dan Statistika

Zakiyatul Fitriyah, Syafira Irsalina, Aditya Rizq Herlandy K, Edy Widodo

Volume 2, No. 3, Desember 2021 hal.282-291

DOI Artikel: 10.46306/lb.v2i3.86

\section{PENDAHULUAN}

Pembangunan menjadi suatu perlengkapan yang dibutuhkan dalam mencapai tujuan suatu bangsa sebaliknya bentuk indikator yang diperlukan suatu negara dalam melihat keberhasilan pembangunan yaitu pertumbuhan ekonomi (Purnamasari, 2019). IPM menjadi tolak ukur untuk meninjau keberhasilan upaya pembangunan mutu tingkat hidup manusia. Indonesia mengalami peningkatan IPM setiap tahunnya (Zarmeila Putri, 2018). Namun jika dilihat per provinsi masih terdapat beberapa provinsi dengan predikat IPM rendah. Provinsi Jawa Barat dan Banten menjadi dua provinsi dengan predikat status IPM tinggi. Meskipun kedua provinsi termasuk menyandang status IPM tinggi, namun keduanya masih memiliki masalah dalam pendidikan karena Rata - Rata Lama Sekolah (RLS) hanya mencapai tingkat SMP. Sedangkan Harapan Lama Sekolah (HLS) di Jawa Barat dan Banten sudah cukup tinggi yaitu diatas 12 atau setara tamat jenjang Diploma I. Jawa Barat dan Banten menjadi bagian 10 provinsi dengan nilai Angka Harapan Hidup (AHH) paling tinggi di Indonesia (BPS Provinsi Jawa Barat, 2020). Namun AHH Banten lebih rendah dibandingkan Jawa Barat. Pada tahun 2020, terdapat beberapa kabupaten/kota di Jawa Barat mengalami penurunan pengeluaran per kapita. Hal ini disebabkan oleh kondisi resesi ekonomi akibat Covid-19. Berdasarkan data BPS, Banten ikut mengalami penurunan pengeluaran per kapita. Bahkan penduduk miskin yang berada di Provinsi Banten tahun 2020 mengalami kenaikan akibat pandemi Covid-19 (BPS Provinsi Jawa Barat, 2020). Sehingga perlu dilakukan analisis faktor - faktor yang memiliki pengaruh terhadap IPM di Jawa Barat dan Banten tahun 2020 dikarenakan terdapat dugaan bahwa pandemi Covid19 yang melanda Indonesia tahun 2020 mempengaruhi faktor - faktor pembentuk IPM. Dalam menganalisis faktor-faktor tersebut diperlukan sebuah metode yakni analisis regresi linear berganda.

Terdapat banyak penelitian terdahulu tentang IPM. Banyak metode yang menjadi alat analisis yakni analisis regresi, data panel, analisis robust, dan lainnya. (Marleni \& Anwar, 2019) dalam penelitiannya dengan analisis linear berganda dalam mengkaji faktor yang memiliki pengaruh pada IPM di Kabupaten Pidie Tahun 2010 - 2017. Hasil penelitian menunjukkan bahwa secara parsial PDRB serta jumlah tenaga kerja mempunyai pengaruh positif serta signifikan, serta kemiskinan mempunyai pengaruh negatif serta signifikan terhadap IPM di Kabupaten Pidie. Sebaliknya secara simultan PDRB, kemiskinan serta jumlah tenaga kerja berpengaruh positif serta signifikan terhadap IPM. Dengan metode sama yaitu regresi linear berganda, (Si'lang \& Priyagus, 2019) mengadakan penelitian untuk mengkaji faktor-faktor yang 
Jurnal Lebesgue: Jurnal Ilmiah Pendidikan Matematika, Matematika dan Statistika

Zakiyatul Fitriyah, Syafira Irsalina, Aditya Rizq Herlandy K, Edy Widodo

Volume 2, No. 3, Desember 2021 hal.282-291

DOI Artikel: 10.46306/lb.v2i3.86

berpengaruh pada IPM Provinsi Sulawesi Barat. Pada penelitian itu diketahui secara simultan PDRB bidang pertanian, belanja langsung pemerintah, investasi swasta, serta tingkat pengangguran terbuka mempunyai pengaruh signifikan pada IPM Sulawesi Barat.

Pada tahun 2020, (Megantara \& Budhi, 2020) melaksanakan penelitian tentang pengaruh AMH serta upah minimum terhadap tingkatan pengangguran serta IPM kabupaten/ kota di Provinsi Bali dengan analisis deskriptif dan analisis jalur. Didapatkan hasil jika AMH, upah minimum memiliki pengaruh positif signifikan, sebaliknya tingkatan pengangguran secara langsung memiliki pengaruh positif tetapi tidak signifikan terhadap IPM kabupaten/ kota Provinsi Bali. Setahun kemudian, (Puspitasari dkk, 2021) dengan penelitian model regresi robust estimasi M untuk IPM di Jawa Timur dengan tujuan melihat faktor dengan pengaruh signifikan pada IPM yang dinantikan dapat meningkatkan IPM wilayah lain. Hasil model regresi robust pembobot Tukey Bisquare yaitu dengan interpretasi bahwa sebesar 99.91\% variabel IPM mampu dipaparkan variabel AHH, pendapatan per kapita, RLS dan HLS sementara itu sebanyak $0.09 \%$ dijelaskan dengan variabel lain pada luar model. Variabel independen mampu memberikan pengaruh yang signifikan pada IPM di Jawa Timur 2019 yakni AHH, pendapatan per kapita, RLS dan HLS.

Tahun 2021, peneliti mengadakan penelitian terbaru mengenai faktor-faktor yang memiliki pengaruh terhadap IPM kabupaten/ kota di Provinsi Jawa Barat dan Banten tahun 2020. Keterbaruan penelitian ini yaitu faktor-faktor yang memiliki pengaruh terhadap IPM tahun 2020 dimana seluruh wilayah di Indonesia dilanda pandemi Covid-19, sehingga diketahui bahwa salah satu faktor yakni pengeluaran per kapita mengalami penurunan yang diakibatkan oleh Covid-19.

Penelitian ini memiliki tujuan yakni mengetahui gambaran umum data IPM dan faktor pembentuknya serta apakah dengan adanya penurunan pada faktor-faktor pembentuk IPM mengakibatkan faktor tersebut tetap berpengaruh atau tidak terhadap IPM kabupaten/ kota di Jawa Barat dan Banten tahun 2020 dengan analisis regresi linear berganda. Dengan diketahuinya gambaran mengenai faktor-faktor tersebut dapat dijadikan acuan untuk membuat kebijakan pemerintah daerah serta bahan masukan serta pertimbangan untuk pemerintah pusat maupun daerah sebagai tolak ukur. 
Jurnal Lebesgue: Jurnal Ilmiah Pendidikan Matematika, Matematika dan Statistika

Zakiyatul Fitriyah, Syafira Irsalina, Aditya Rizq Herlandy K, Edy Widodo

Volume 2, No. 3, Desember 2021 hal.282-291

DOI Artikel: 10.46306/lb.v2i3.86

\section{METODE PENELITIAN}

\section{Data dan Sumber Data}

Data sekunder penelitian ini bersumber dari Badan Pusat Statistik (BPS) Republik Indonesia mengenai faktor pembentuk IPM kabupaten/ kota di Jawa Barat dan Banten tahun 2020 yang variabelnya dijelaskan dalam Tabel 1 (BPS-Statistics Indonesia, 2020).

\section{Definisi Variabel}

Variabel yakni atribut objek yang memiliki variasi tertentu, serta telah dipilih peneliti untuk dipelajari serta diambil kesimpulan (Sugiyono, 2017). Definisi variabel diuraikan dalam Tabel 1 (BPS Provinsi Jawa Barat, 2020).

Tabel 1. Definisi Variabel Penelitian

\begin{tabular}{|c|c|c|}
\hline Variabel & Definisi Variabel & Satuan \\
\hline $\mathrm{IPM}(\mathrm{Y})$ & $\begin{array}{l}\text { Persentase indikator mengukur tingkat keberhasilan } \\
\text { penduduk menjangkau hasil pembangunan dalam } \\
\text { mendapatkan penghasilan, kesehatan serta } \\
\text { pendidikan }\end{array}$ & $\begin{array}{c}\text { Persen } \\
\text { per } \\
\text { Tahun }\end{array}$ \\
\hline $\mathrm{AHH}\left(\mathrm{X}_{1}\right)$ & $\begin{array}{l}\text { Rata-rata perkiraan jumlah tahun yang mampu } \\
\text { dilalui seseorang selama hidup }\end{array}$ & Tahun \\
\hline $\operatorname{RLS}\left(\mathrm{X}_{2}\right)$ & $\begin{array}{l}\text { Rata-rata jumlah tahun penduduk usia }>15 \text { tahun } \\
\text { dalam menempuh pendidikan formal }\end{array}$ & Tahun \\
\hline $\operatorname{HLS}\left(\mathrm{X}_{3}\right)$ & $\begin{array}{l}\text { Nilai lamanya sekolah yang diharapkan dilalui anak } \\
\text { umur tertentu di masa yang akan datang }\end{array}$ & Tahun \\
\hline $\begin{array}{l}\text { Pengeluaran } \\
\text { Per Kapita }\left(\mathrm{X}_{4}\right)\end{array}$ & Rata-rata jumlah pengeluaran per kapita riil & Rupiah \\
\hline
\end{tabular}

\section{METODE PENELITIAN}

Analisis deskriptif dan analisis regresi linear berganda merupakan metode analisis dalam penelitian ini. Dimana regresi linear berganda menjadi analisis diantara dua atau lebih variabel independen $\left(\mathrm{X}_{1}, \mathrm{X}_{2}, \ldots, \mathrm{X}_{\mathrm{n}}\right)$ dengan dependen $(\mathrm{Y})$ dalam melihat tingkat hubungan keduanya secara linear (Janie, 2012). Persamaan matematis dari regresi linear berganda (Yuliara, 2016):

$$
Y_{i}=\beta_{0}+\beta_{1} X_{1 i}+\beta_{2} X_{2 i}+\cdots+\beta_{k} X_{k i}+\varepsilon_{i}
$$


dengan:

$$
\begin{array}{ll}
X_{k i} & =\text { variabel independen ke- } k \\
Y_{i} & =\text { variabel dependen ke- } i \\
\beta_{0} & =\text { konstanta } \\
\beta_{k} & =\text { nilai parameter variabel independen ke- } k \\
\varepsilon_{i} & =\text { variabel } \text { error acak } \\
i & =1,2,3, \ldots, n
\end{array}
$$

Alat bantu yang digunakan berupa software R Studio, SPSS dan Microsoft Excel. Gambar 1 menyajikan flowchart tentang tahapan penelitian ini.

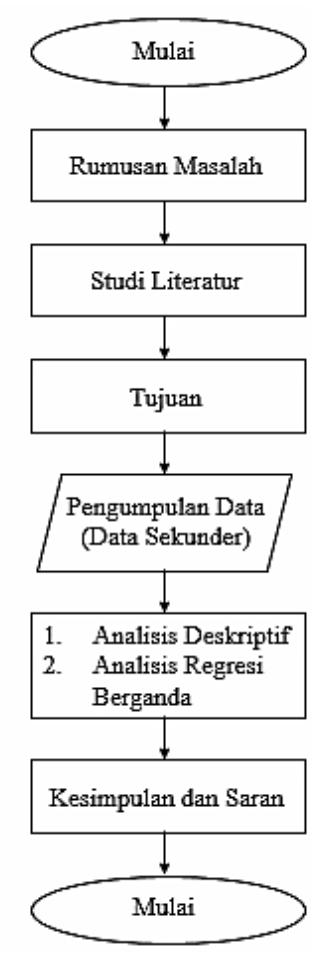

Gambar 1. Flowchart Penelitian

Mulai penelitian dengan melakukan perumusan masalah yang diangkat dalam penelitian. Berikutnya, mengadakan studi literatur dari berbagai sumber diantaranya dari jurnal, tesis, skripsi, serta website resmi lainnya. Selanjutnya, menentukan tujuan penelitian serta mengumpulkan data dimana data sekunder diperoleh dari website BPS Republik Indonesia. Kemudian dilakukan tahap analisis data yakni analisis deskriptif dan regresi linear berganda. Selain itu, dari hasil penelitian diperoleh kesimpulan dan penelitian dianggap selesai. 
Jurnal Lebesgue: Jurnal Ilmiah Pendidikan Matematika, Matematika dan Statistika

Zakiyatul Fitriyah, Syafira Irsalina, Aditya Rizq Herlandy K, Edy Widodo

Volume 2, No. 3, Desember 2021 hal.282-291

DOI Artikel: 10.46306/lb.v2i3.86

\section{HASIL DAN PEMBAHASAN}

\section{Statistika Deskriptif}

Gambaran umum data IPM, AHH, RLS, HLS dan pengeluaran per kapita di Jawa Barat dan Banten tahun 2020 dilihat dari statistika deskriptif.

Tabel 2. Statistika Deskriptif

\begin{tabular}{lrrrrr}
\hline \multicolumn{1}{c}{ Variabel } & N & \multicolumn{1}{c}{ Mean } & Minimum & Maximum & Median \\
\hline IPM atau Y (\%) & 35 & 71.62 & 63.91 & 81.51 & 70.82 \\
AHH atau X (tahun) & 35 & 71.30 & 64.64 & 75.01 & 71.83 \\
RLS atau X (tahun) & 35 & 8.60 & 6.3 & 11.81 & 8.3 \\
HLS atau X (tahun) & 35 & 12.87 & 11.7 & 14.47 & 12.78 \\
Pengeluaran Per Kapita & 35 & $11,024.77$ & 7852 & 16,887 & 10,535 \\
atau X & & & & \\
\hline
\end{tabular}

Tabel 2. adalah statistika deskriptif tiap-tiap variabel. Beberapa nilai statistik yaitu jumlah observasi (dilambangkan N), rata-rata (atau mean), nilai terkecil (atau minimum), nilai tertinggi (atau maximum), dan nilai tengah (atau median) variabel IPM, AHH, RLS, HLS dan pengeluaran per kapita.

\section{Identifikasi Variabel Dependen dan Independen}

Sebelum analisis, dilakukan identifikasi dengan scatterplot untuk melihat pola hubungan antara variabel independen dan dependen.
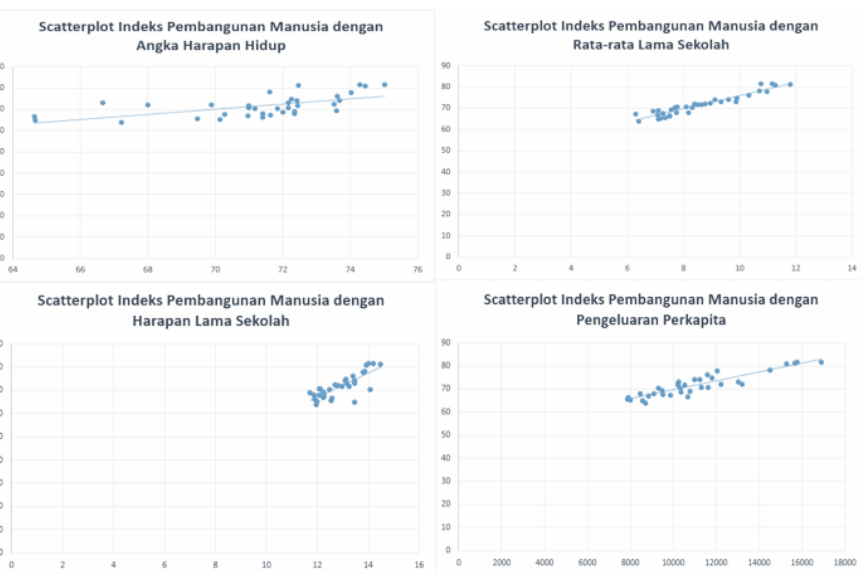

Gambar 2. Scatterplot antara IPM dengan Faktor Pembentuk IPM 
Jurnal Lebesgue: Jurnal Ilmiah Pendidikan Matematika, Matematika dan Statistika

Zakiyatul Fitriyah, Syafira Irsalina, Aditya Rizq Herlandy K, Edy Widodo

Volume 2, No. 3, Desember 2021 hal.282-291

DOI Artikel: 10.46306/lb.v2i3.86

Pada Gambar 2. terlihat titik - titik persebaran data membentuk pola garis miring lurus ke atas berarti ada hubungan linear positif antara variabel independen dengan dependen. Artinya jika AHH, RLS, HLS, dan pengeluaran per kapita mengalami kenaikan maka IPM juga akan mengalami kenaikan.

\section{Estimasi Persamaan Regresi Linear Berganda}

Untuk menunjukkan hubungan antara $\mathrm{X}_{1}, \mathrm{X}_{2}, \mathrm{X}_{3}$ dan $\mathrm{X}_{4}$ terhadap $\mathrm{Y}$ digunakan regresi linear berganda yang membentuk model estimasi. Model estimasi awalnya adalah

$$
\hat{Y}=5.317+0.4683 \mathrm{X}_{1}+1.257 \mathrm{X}_{2}+0.9853 \mathrm{X}_{3}+
$$
$0.0008545 \mathrm{X}$

\section{Diagnostic Checking}

Uji kelayakan model diperlukan dalam tahapan analisis regresi linear berganda meliputi uji overall, uji parsial, serta koefisien determinasi.

1. Uji Overall (Uji F)

Tabel 3. Statistik Uji F: ANOVA

\begin{tabular}{cccccc}
\hline & Sum of Square & df & Mean Square & F-hitung & Sig. $\left(\boldsymbol{p}_{\text {-value }}\right)$ \\
\hline Regression & 846.343 & 4 & 211.586 & & \\
Residual & 2.188 & 30 & 0.073 & 2900.591 & $.000^{\mathrm{b}}$ \\
\cline { 1 - 4 } Total & 848.532 & 34 & & &
\end{tabular}

Pada pengujian overall diperoleh nilai $F_{\text {hitung }}=2009.591>F_{(0.05 ; 4,30)}=2,689628$ maka tolak $\mathrm{H}_{0}$ sehingga model regresi layak digunakan. Artinya secara bersama-sama variabel independen $\mathrm{AHH}\left(\mathrm{X}_{1}\right)$, RLS $\left(\mathrm{X}_{2}\right)$, HLS $\left(\mathrm{X}_{3}\right)$ dan pengeluaran per kapita $\left(\mathrm{X}_{4}\right)$ memiliki pengaruh pada variabel dependen IPM (Y) tahun 2020 tiap kabupaten/ kota di Jawa Barat dan Banten.

\section{Uji Parsial (Uji t)}

Tabel 4. Statistik Uji t

\begin{tabular}{lcccc}
\hline Variabel & Koef. Regresi & $t_{\text {hitung }}$ & $p_{\text {-value }}$ & Keputusan \\
\hline Konstanta & 5.317 & 2.805 & 0.00875 & \\
AHH $\left(\mathrm{X}_{1}\right)$ & 0.4682 & 21.604 & 0.00000 & Tolak $\mathrm{H}_{0}$
\end{tabular}


Jurnal Lebesgue: Jurnal Ilmiah Pendidikan Matematika, Matematika dan Statistika

Zakiyatul Fitriyah, Syafira Irsalina, Aditya Rizq Herlandy K, Edy Widodo

Volume 2, No. 3, Desember 2021 hal.282-291

DOI Artikel: $10.46306 /$ lb.v2i3.86

$\begin{array}{lccc}\text { RLS }\left(\mathrm{X}_{2}\right) & 1.257 & 17.065 & 0.00000 \\ \text { HLS }\left(\mathrm{X}_{3}\right) & 0.9853 & 9.427 & 0.00000 \\ \text { Pengeluaran Per Kapita }\left(\mathrm{X}_{4}\right) & 0.0008545 & 24.369 & 0.00000\end{array}$

Hasil uji parsial diperoleh nilai $t_{\text {hitung }}\left(\mathrm{X}_{1}\right)$ sebesar 21.604, $\left(\mathrm{X}_{2}\right)$ sebesar 17.065, $\left(\mathrm{X}_{3}\right)$ sebesar 9.427, dan $\left(\mathrm{X}_{4}\right)$ sebesar 24.369. Nilai $t_{\text {hitung }}$ seluruh variabel menunjukkan $t_{\text {hitung }}>$ $t(30,0.05)=2.042$ maka tolak $\mathrm{H}_{0}$ artinya koefisien regresi signifikan dalam model.

\section{Koefisien Determinasi}

Tabel 5. Koefisien Determinasi

\begin{tabular}{ccccc}
\hline Model & $R$ & $R$ Square & Adjusted $R$ Squared & Std. Error of the Estimate \\
\hline 1 & $.999^{\mathrm{a}}$ & .997 & .997 & .27008 \\
\hline
\end{tabular}

Hasil analisis menunjukkan nilai $R^{2}$ yaitu 0.997 yang artinya 99.7\% variasi IPM tahun 2020 kabupaten/ kota di Jawa Barat dan Banten yang diuraikan dengan besarnya faktor pembentuk yaitu variabel AHH, RLS, HLS dan pengeluaran per kapita. Sementara itu, $0.03 \%$ lainnya dijelaskan dengan variabel lain yang berada diluar model pada penelitian ini.

\section{Uji Asumsi Klasik}

Estimasi model yang terbentuk wajib memiliki sifat BLUE (Best Linear Unbiased Estimator) serta asumsi residual model regresi wajib memenuhi kriteria IIDN atau identik, independen, dan berdistribusi normal.

\section{Uji Normalitas}

Untuk mengetahui bahwa sampel data variabel IPM, AHH, RLS, HLS, dan pengeluaran per kapita berasal dari populasi dengan distribusi normal ataukah tidak dengan statistik uji Kolmogorov-Smirnov. Pada hasil pengujian diperoleh nilai $D_{\text {hitung }}=$ $0.14316<D_{(35,0.05)}=0.22424$ maka gagal tolak $\mathrm{H}_{0}$ berarti data berasal dari distribusi normal.

\section{Uji Multikolinearitas}

Untuk mengetahui adanya korelasi antar variabel independen AHH, RLS, HLS, dan pengeluaran per kapita menggunakan nilai VIF. Diperoleh nilai $V I F$ variabel $\left(\mathrm{X}_{1}\right)=1.39$, 
Jurnal Lebesgue: Jurnal Ilmiah Pendidikan Matematika, Matematika dan Statistika

Zakiyatul Fitriyah, Syafira Irsalina, Aditya Rizq Herlandy K, Edy Widodo

Volume 2, No. 3, Desember 2021 hal.282-291

DOI Artikel: 10.46306/lb.v2i3.86

$\left(X_{2}\right)=5.82,\left(X_{3}\right)=3.11$, dan $\left(X_{4}\right)=3.19$. Oleh karena keempat variabel memiliki nilai

$V I F \leq 10$ maka gagal tolak $\mathrm{H}_{0}$ artinya tidak terdapat multikolinearitas.

\section{Uji Homoskedastisitas}

Untuk mengetahui ketidaksamaan varians residual antara IPM, AHH, RLS, HLS, dan pengeluaran per kapita. Diperoleh nilai $B P=1.2936<\chi_{(0.05 ; 4)}^{2}=9.4877$ maka gagal tolak $\mathrm{H}_{0}$ artinya terjadi homoskedastisitas.

\section{Uji Autokorelasi}

Untuk melihat apakah regresi yang digunakan ada korelasi antara kesalahan pengganggu saat periode sebelum dan sesudahnya menggunakan statistik uji Durbin Watson. Diperoleh hasil pengujian nilai $D W=1.9815$. Sehingga $d u=1.7259<1.98<$ $4-d u=2.2471$ maka gagal tolak $\mathrm{H}_{0}$ berarti tidak terdapat autokorelasi.

\section{Interpretasi Model Terbaik Hasil Regresi Linear Berganda}

Pada hasil analisis didapatkan persamaan regresi terbaik dalam penelitian ini yang ditulis pada persamaan (3):

$$
Y=5.317+0.4683 \mathrm{X}_{1}+1.257 \mathrm{X}_{2}+0.9853 \mathrm{X}_{3}+
$$

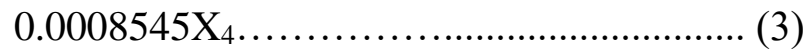

dengan: $\mathrm{Y}=\mathrm{IPM}$ (dalam \% per tahun), $\mathrm{X}_{1}=\mathrm{AHH}$ (dalam tahun), $\mathrm{X}_{2}=\mathrm{HLS}$ (dalam tahun), $\mathrm{X}_{3}=\mathrm{RLS}$ (dalam tahun), $\mathrm{X}_{4}=$ pengeluaran per kapita (dalam Rupiah)

Hasil regresi linear berganda pada persamaan (3) diinterpretasikan untuk $\mathrm{X}_{1}$ apabila setiap perubahan satu tahun pada $\mathrm{AHH}$ dengan menganggap variabel yang lain bernilai konstan menyebabkan perubahan IPM sebesar $0.4683 \%$. Sedangkan, untuk $\mathrm{X}_{2}$ apabila setiap perubahan satu tahun pada RLS dengan menganggap variabel yang lain bernilai konstan menyebabkan perubahan IPM sebesar $1.257 \%$. Kemudian, $\mathrm{X}_{3}$ jika setiap perubahan satu tahun pada HLS dengan menganggap variabel lain bernilai konstan menyebabkan perubahan IPM sebesar $0.9853 \%$. Selanjutnya, $\mathrm{X}_{4}$ apabila setiap perubahan satu rupiah pada pengeluaran per kapita dengan menganggap variabel lain bernilai konstan menyebabkan perubahan IPM sebesar $0.000854 \%$.

\section{KESIMPULAN}

Pada hasil analisis yang telah dipaparkan sebelumnya, didapatkan dua kesimpulan yang mampu memberikan jawaban atas rumusan masalah dalam penelitian ini yaitu gambaran umum 
Jurnal Lebesgue: Jurnal Ilmiah Pendidikan Matematika, Matematika dan Statistika

Zakiyatul Fitriyah, Syafira Irsalina, Aditya Rizq Herlandy K, Edy Widodo

Volume 2, No. 3, Desember 2021 hal.282-291

DOI Artikel: 10.46306/lb.v2i3.86

dari data IPM dan faktor pembentuknya di Provinsi Jawa Barat dan Banten bahwa nilai IPM paling tinggi diduduki Kota Bandung dengan IPM sebesar $81.51 \%$ per tahun, nilai AHH paling tinggi diduduki Kota Bekasi dengan nilai AHH sebesar 75.01 tahun, nilai RLS dan HLS paling tinggi diduduki Kota Tangerang Selatan dengan nilai RLS sebesar 11.81 tahun dan nilai HLS sebesar 14.47 tahun, serta pengeluaran per kapita paling tinggi diduduki Kota Bandung sebesar Rp 16,887 per kapita per tahun.

Berdasarkan pada hasil analisis regresi linear berganda, diperoleh hasil dengan menggunakan tingkat keyakinan 95\% data yang ada menunjukkan bahwa variabel AHH, RLS, HLS dan pengeluaran per kapita memiliki pengaruh yang positif signifikan pada variabel IPM tahun 2020 kabupaten/ kota di Provinsi Jawa Barat dan Banten. Dari analisis juga didapatkan bahwa kemampuan model untuk menjelaskan masalah adalah 99.7\%. Sehingga model estimasi paling baik dalam melakukan estimasi parameter pada IPM tahun 2020 yaitu $5.317+0.4683 \mathrm{X}_{1}$ $+1.257 \mathrm{X}_{2}+0.9853 \mathrm{X}_{3}+0.0008545 \mathrm{X}_{4}$

\section{DAFTAR PUSTAKA}

Badan Pusat Statistika Indonesia. (2020). Indeks Pembangunan Indonesia. https://www.bps.go.id/subject/26/indeks-pembangunan-manusia.html\#subjekViewTab3

BPS Provinsi Jawa Barat. (2020). Indeks Pembangunan Manusia Provinsi Jawa Barat. BPS Provinsi Jawa Barat.

Janie. (2012). Statistika Deskriptif \& Regresi Linear Berganda dengan SPSS. Semarang University Press.

Marleni, Lena dan Anwar, K. (2019). Faktor-Faktor Yang Mempengaruhi Indeks Pembangunan Manusia Di Kabupaten Pidie Tahun 2010 - 2017. Jurnal Ekonomi Regional Unimal, 2(2), 109-116. https://ojs.unimal.ac.id/ekonomi_regional/article/view/1690

Megantara, D. E., Kembar, M., \& Budhi, S. (2020). Pengaruh Angka Melek Huruf Dan Upah Minimum Terhadap Tingkat Pengangguran Dan Indeks Pembangunan Manusia Kabupaten / Kota Di Provinsi Bali. Jurnal Ekonomi Pembangunan Universitas Udayana, 9(1), 91-119.

Purnamasari, S. (1992). Penerapan Ekonomi Pembangunan (Vol. 5, Issue 1).

Putri, Z. (2018). Pemodelan Indeks Pembangunan Manusia Menggunakan Geographically Weighted Regression (GWR) (Studi Kasus: Indeks Pembangunan Manusia di Indonesia Tahun 2016). Universitas Islam Indonesia.

Tiara, M., Puspitasari, S., Susanti, Y., \& Sulistijowati, S. (2021). Model Regresi Robust untuk Indeks Pembangunan Manusia di Jawa Timur dengan Estimasi M. PRISMA, Prosiding Seminar Nasional Matematika, 4(01), 659-665.

Yuliara. (2016). Modul Regresi Linear Berganda. Fakultas Matematika dan Ilmu Pengetahuan Alam Universitas Udayana.

Zamruddin Hasid, P. I. L. S. S. (2019). Analisis faktor-faktor yang berpengaruh terhadap indeks pembangunan manusia Analysis on factors affecting to human development index in sulawesi barat province. Jurnal Manajemen, 11(2), 159-169. http://journal.feb.unmul.ac.id/index.php/JURNALMANAJEMEN 